\title{
Seasonal Species Composition and Abundance of Rodents in Yerer Mountain Forest Area, Central Ethiopia
}

\author{
Yonas Terefe $^{1}$, Fikresilasie Samuel ${ }^{2}$ \\ ${ }^{1}$ Department of Biology, Ambo University, Ambo, Ethiopia \\ ${ }^{2}$ Department of Medicine, Ambo University, Ambo, Ethiopia \\ Email address: \\ yonasterefe56@gmail.com (Y. Terefe), fikre16sam@gmail.com (F. Samuel)
}

\section{To cite this article:}

Yonas Terefe, Fikresilasie Samuel. Seasonal Species Composition and Abundance of Rodents in Yerer Mountain Forest Area, Central Ethiopia. American Journal of BioScience. Vol. 3, No. 3, 2015, pp. 87-92. doi: 10.11648/j.ajbio.20150303.14

\begin{abstract}
An ecological study on the seasonal species composition and abundance of rodents was carried out in the farmland, bushland, forest and grassland habitats of Yerer Mountain Forest Area from July 2010 to March 2011. From a total of 3312 trap nights, 402 individuals of small mammals were captured. Out of these, 400 (99.5\%) individuals represented 6 species of the family Muridae and whereas the remaining $2(0.5 \%)$ belonged to one shrew species (family Soricidae). The seasonal species composition within each habitat was not significant. But there was significant variation in their relative abundance during wet and dry seasons. High mean trap success (23.5\%) and biomass (4151g/hectare) was obtained from the farmland habitat. Number of pregnant females and embryo count showed seasonal variation. Stomach content analysis showed high proportion of plant matter in all samples.
\end{abstract}

Keywords: Species Composition, Abundance, Trap Success, Biomass, Rodents

\section{Introduction}

Mammals are quite diverse both structurally as well as functionally. There are more than 5,000 extant mammalian species recognized throughout the world. Of all the mammalian orders, Rodentia constitute the largest number of species with more than 2,000 species within 32 extant families (Feldhamer et al. 2007; Kingdon, 1997; Vaughan et al. 2000). In Africa, there are about 14 families, 89 genera and 290 species of rodents. They are the most ubiquitous and abundant among the mammals (Mengistu and Bekele, 2003). East Africa has a wide variety of rodents. Most of them are endemic and account for about $28 \%$ of the total East African mammal fauna (Kingdon, 1997). Among the 284 species of mammals of Ethiopia, 31 are endemic, of which rodents hold $50 \%$ of the endemics (Bekele and Corti, 1997).The species richness of this order is the result of succession of radiation, adaptation and diversification (Auffray et al. 2009).

Among others, rodent community structure and species composition have been related to habitat structure and complexity, area productivity, predation, trampling and grazing, surrounding landscape and the distance between similar habitats, succession of the vegetation and the presence of exotics (Avenant and Cavallini, 2007). The dynamics of population in many small mammals is the result of the combined effects of feedback structure (ecological interactions within and between populations), limiting factors (food, or predator), climatic factors (rainfall), and stochastic forces (Andreo et al. 2008).

Basically, rodent population exhibits a great seasonal and year to year variation. Their distribution pattern and relative abundance vary seasonally based on availability of food and vegetation cover. The seasonal distribution and quantity of rainfall are considered as major climatic variable in determining population dynamics of rodents in East Africa (Delany and Monro, 1985). The onset of the rainy season is swiftly followed by the appearance of good ground cover and quality diet leading to increased rate of reproduction. Population outbreak of many species of rodents occurs when prolonged rainfall allows better survival of the young. The driving factors for rodent outbreak could be climatic fluctuations and environmental variations (Bekele and Leirs, 1997).

Few ecological studies on the seasonal species composition of rodents have been carried out in different parts of Ethiopia. So far, no studies have been conducted on rodents in the area. The present study aimed to investigate the seasonal species composition and abundance of rodents in Yerer Mountain Forest Area, Central Ethiopia. 


\section{Materials and Methods}

\subsection{Study Area}

The study was conducted in the Yerer Mountain forest area (40 km far from the capital city Addis Ababa, between $8^{\circ}$ $52^{\prime} 00^{\prime \prime} \mathrm{N}$ and 38 $\left.59^{\prime} 30^{\prime \prime} \mathrm{E}\right)$. The mountain covers a total area of 6000 hectares with altitudinal ranges of $2000 \mathrm{~m}$ to the highest peak at 3100 masl. The area receives mean annual rainfall of $1000 \mathrm{~mm}$ with average minimum and maximum temperature of $10^{\circ} \mathrm{C}$ and $26^{\circ} \mathrm{C}$, respectively. It is characterized by a unimodal rainfall having long rainy season. The area receives the highest rainfall during the wet season from June to September. Short rains occur at any months of the dry season, especially during March, April and May.

Vegetation composition of this study area is characterized by both natural forest (dominated by Juniperusprocera) and man- made plantations. The upper part of the mountain is highly dominated by bushes and shrubs. The most common species of shrubs are Carisaedulis, Alophylusabyssinicus, Maytenusarbutifolia, M. unduta, Erica arborea, Buddlejapolystachya, Nuxicongesta, Entadaabyssinica, Rosa abyssinica, Grewiaferruginea, G. villosa and Hypericumrevolutum. The man-made plantation is dominated by exotic plant species such as Eucalyptusglobulus, E. camaldulensis and Cuppressuslustanica.

The area also supports diverse groups of bird species and fewer larger mammals. The most conspicuous large mammals in the area are Klipspringer (Oreotragusoreotragus), Menelik's bushbuck (Tragelapphusscriptusmeneliki), Bush duiker (Sylvicapragrimmia), Anubis baboon (PapioAnubis), Warthog (Phacochoerusaethiopicus) and the spotted hyeana (Crocutacrocuta).

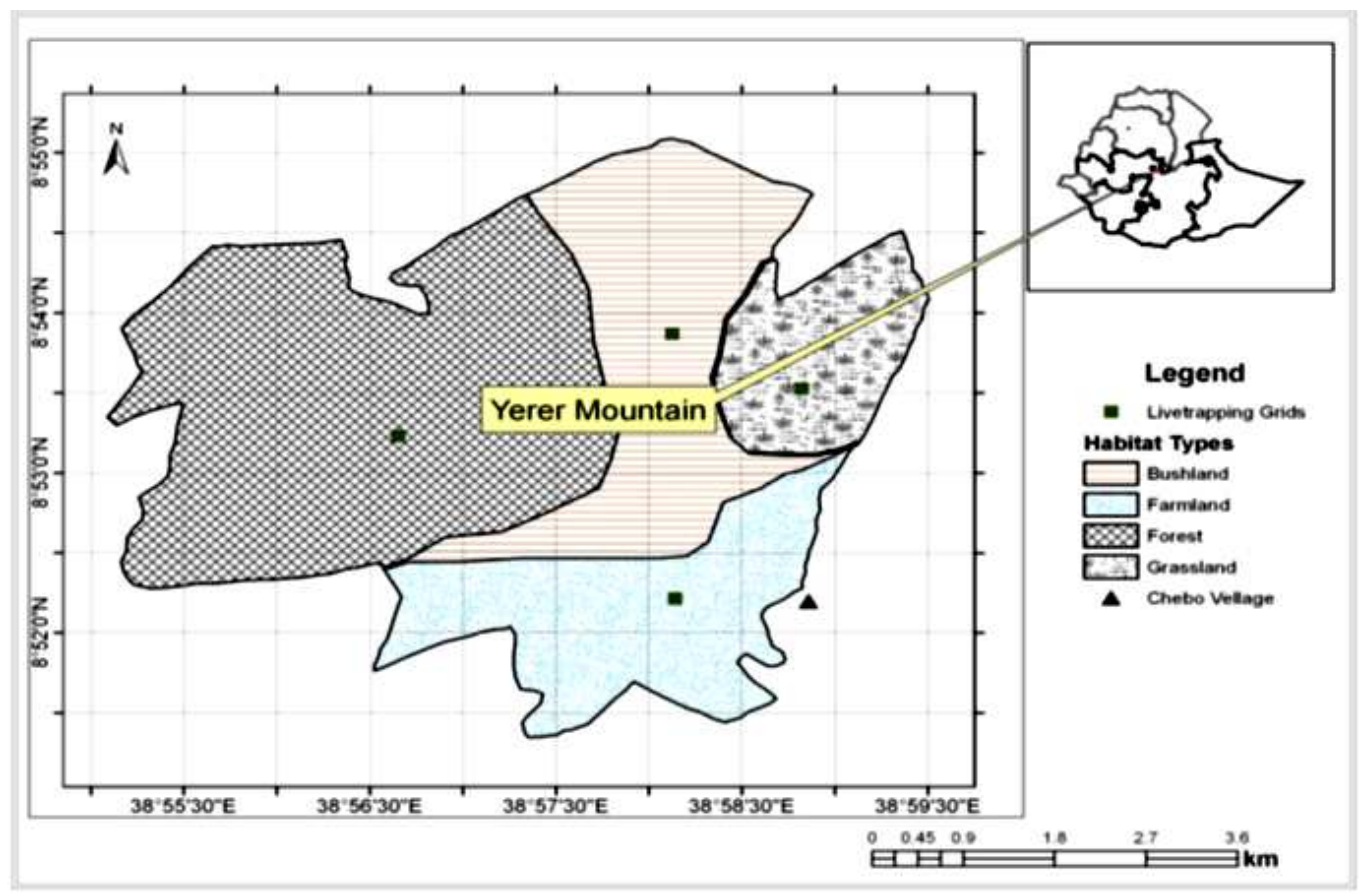

Figure 1.Map of the study area.

\subsection{Study Design}

Based on the topography and vegetation type, the study area was classified into, forest (FO), bushland (BL), farmland (FL) and grassland (GL) habitats. The representative live-trap grids were established randomly among the vegetation type based upon possible representation of different habitats. Each grid constituted an area of $4900 \mathrm{~m}^{2}(70 \times 70 \mathrm{~m})$. Data collection was made in four trapping sessions (data collection periods). The wet season data was collected from August 2010 to October 2010 consisting of two trapping sessions. The dry season data collection was accomplished in between November 2010 and March 2011. During both seasons, data collection was performed by using Sherman live-traps and snap-traps. Sherman live traps to trap live rodents and for the analysis of stomach content and embryo count, snap-traps were used.
Comparison of seasonal species composition and habitat association of species in the study area, were made by Chisquare tests using SPSS Version 17.0 statistical program. The total number of trapped individuals and the overall trap night were used to compute trap success. The mean weight of each species was used to infer the study areas biomass. Stomach content analysis was made through calculating the mean percentage proportion of food fragments per slides.

\section{Results}

During both wet and dry seasons, a total of 7 species of rodents were recorded from Yerer Mountain Forest area. From a total of 3312 trap nights, 402 individuals of small mammals were captured (Table 1). Out of these, 400 (99.5\%) individuals represented 6 species of the family Muridae and whereas the remaining $2(0.5 \%)$ belonged to one shrew 
species (family Soricidae).

Table 1. Species abundance of rodents in Yerer Mountain Forest Area.

\begin{tabular}{lll}
\hline Species & Total Catch & Abundance (\%) \\
\hline Lophuromysflavopunctatus & 127 & 31.6 \\
Arvicanthisdembeensis & 66 & 16.4 \\
Arvicanthisabyssinicus & 71 & 17.6 \\
Stenocephalemysalbipes & 72 & 18.0 \\
Musmahomet & 55 & 13.7 \\
Dendromysmystacalis & 9 & 2.2 \\
Crocidurafumosa & 2 & 0.5 \\
Total (7 species) & 402 & 100 \\
\hline
\end{tabular}

The seasonal species composition and distribution of livetrapped rodents among the different habitats are given in Table 2. Except for D. mystacalis and C. fumosa, all the remaining species of rodents were trapped during both wet and dry seasons. Dendromysmystacalis was trapped only during the dry season from the grassland habitat, whereas, $C$. fumosa was trapped only from the farmland habitat during the wet season. Out of the total captured individuals (307), $152(49.5 \%)$ individuals were trapped during the wet season and $155(50.5 \%)$ during the dry season.

The difference in species composition between habitats during wet and dry seasons was not statistically significant $\left(\mathrm{x}^{2}=2.3, \mathrm{df}=2, \mathrm{P}>0.05\right.$ and $\mathrm{x}^{2}=3.6, \mathrm{df}=2, \mathrm{P}>0.05$, respectively). The highest (138) as well as the lowest (21) numbers of individuals were recorded during both seasons from the farmland and forest habitats, respectively. During the dry season, the total number of trapped individuals increased from 35 to 51 in the grassland habitat. Conversely, the total number of rodents captured from the bushland habitat declined from 40 to 22 . The difference between abundance of rodents between habitats during wet and dry seasons was statistically significant $\left(\mathrm{x}^{2}=34.7, \mathrm{df}=3, \mathrm{P}<0.05\right.$ and $\mathrm{x}^{2}=76.1, \mathrm{df}=3, \mathrm{P}<0.05$, respectively).

Table 2. Seasonal species composition and abundance of live-trapped rodents from different habitats.

\begin{tabular}{|c|c|c|c|c|c|c|c|c|c|}
\hline \multirow{3}{*}{ Species } & \multicolumn{8}{|c|}{ Habitat types and seasons } & \multirow{3}{*}{ Total } \\
\hline & \multicolumn{2}{|c|}{ Farmland } & \multicolumn{2}{|c|}{ Bushland } & \multicolumn{2}{|c|}{ Forest } & \multicolumn{2}{|c|}{ Grassland } & \\
\hline & Wet & Dry & Wet & Dry & Wet & Dry & Wet & Dry & \\
\hline L.flavopunctatus & 14 & 5 & 27 & 15 & - & - & 19 & 23 & 103 \\
\hline A.dembeensis & 36 & 2 & - & 2 & - & - & - & - & 40 \\
\hline A. abyssinicus & 3 & 59 & - & - & - & - & - & - & 62 \\
\hline S. albipes & - & - & 10 & 3 & 13 & 6 & 5 & 6 & 43 \\
\hline M. mahomet & 8 & 9 & 3 & 2 & 1 & 1 & 11 & 14 & 49 \\
\hline D. mystacalis & - & - & - & - & - & - & - & 8 & 8 \\
\hline C. fumosa & 2 & - & - & - & - & - & - & - & 2 \\
\hline Sum & 63 & 75 & 40 & 22 & 14 & 7 & 35 & 51 & 307 \\
\hline Total (\%) & \multicolumn{2}{|c|}{$138(45.0)$} & \multicolumn{2}{|c|}{$62(20.2)$} & \multicolumn{2}{|c|}{$21(6.8)$} & \multicolumn{2}{|c|}{$86(28.0)$} & \\
\hline Trap Success $(\%)$ & 21.4 & 25.5 & 13.6 & 7.5 & 4.8 & 2.4 & 11.9 & 17.3 & \\
\hline
\end{tabular}

$(-)$ shows absence of trapped individuals.

The highest number of species from the farmland habitat was registered during the wet season, whereas, the least number of species was registered from the forest habitat during both wet and dry season. The other two habitats (bushland and grassland) harbored similar number of species during both seasons. The success of trapping different species varied between habitats as well as seasons (Table 2). Farmland habitat had the highest mean trapping success $(23.5 \%)$ followed by the grassland habitat with a mean trap success of $14.6 \%$. The lowest mean trap success $(3.2 \%)$ was recorded from the forest habitat during the wet and dry seasons. The mean trap success in the bushland habitat was
$10.5 \%$. There was statistical variation in the trap success between the different habitat types during the two seasons $\left(\mathrm{x}^{2}=17.2, \mathrm{df}=3, \mathrm{P}<0.05\right)$.

The sex ratio of trapped rodents from different habitats during the wet and dry seasons is given in Table 3. Out of the overall individuals captured by live-trap, females comprised $103(33.5 \%)$ and males 204 (66.5\%). The sex ratio of males captured from the different habitats was higher than females during wet as well as dry seasons. The ratio for males was also higher within each species during all trapping sessions. The difference in sex ratio of females and males was statistically significant $\left(\mathrm{x}^{2}=33.2, \mathrm{df}=1, \mathrm{P}<0.01\right)$.

Table 3. Sex ratio of live-trapped rodents during the wet and dry seasons.

\begin{tabular}{|c|c|c|c|c|c|c|c|c|c|}
\hline \multirow{3}{*}{ Habitat } & \multirow{3}{*}{ Season } & \multicolumn{8}{|c|}{ Number of male and female individuals trapped for each species } \\
\hline & & \multicolumn{2}{|l|}{ L.f } & \multicolumn{2}{|l|}{ A.d } & \multicolumn{2}{|l|}{ A. $a$} & \multicolumn{2}{|l|}{ S.a } \\
\hline & & $\mathbf{M}$ & $\mathbf{F}$ & M & $\mathbf{F}$ & M & $\mathbf{F}$ & M & $\mathbf{F}$ \\
\hline \multirow{2}{*}{ FL } & Wet & 9 & 5 & 19 & 17 & 2 & 1 & - & - \\
\hline & Dry & 4 & 1 & 2 & - & 35 & 24 & - & - \\
\hline \multirow{2}{*}{ BL } & Wet & 17 & 10 & - & - & - & - & 8 & 2 \\
\hline & Dry & 11 & 4 & 2 & - & - & - & 3 & - \\
\hline FO & Wet & - & - & - & - & - & - & 8 & 5 \\
\hline \multirow{2}{*}{ GL } & Wet & 12 & 7 & - & - & - & - & 3 & 2 \\
\hline & Dry & 18 & 5 & - & - & - & - & 6 & - \\
\hline Total(\%) & & $71(23.1)$ & $32(10.4)$ & $23(7.5)$ & $17(5.5)$ & $37(12.0)$ & $25(8.1)$ & $33(10.8)$ & $10(3.3)$ \\
\hline
\end{tabular}


Table 3. Continue.

\begin{tabular}{|c|c|c|c|c|c|c|c|c|c|}
\hline \multirow{3}{*}{ Habitat } & \multirow{3}{*}{ Season } & \multicolumn{8}{|c|}{ Number of male and female individuals trapped for each species } \\
\hline & & \multicolumn{2}{|l|}{ M.m } & \multicolumn{2}{|l|}{ D.m } & \multicolumn{2}{|l|}{ C.f } & \multicolumn{2}{|l|}{ Total } \\
\hline & & $\mathbf{M}$ & $\mathbf{F}$ & $\mathbf{M}$ & $\mathbf{F}$ & M & $\mathbf{F}$ & M & $\mathbf{F}$ \\
\hline \multirow{2}{*}{ FL } & Wet & 4 & 4 & - & - & 2 & - & 36 & 27 \\
\hline & Dry & 7 & 2 & - & - & - & - & 48 & 27 \\
\hline \multirow{2}{*}{$\mathrm{BL}$} & Wet & 2 & 1 & - & - & - & - & 27 & 13 \\
\hline & Dry & 2 & - & - & - & - & - & 18 & 4 \\
\hline \multirow{2}{*}{ FO } & Wet & 1 & - & - & - & - & - & 9 & 5 \\
\hline & Dry & 1 & - & - & - & - & - & 6 & 1 \\
\hline \multirow{2}{*}{ GL } & Wet & 7 & 4 & - & - & - & - & 22 & 13 \\
\hline & Dry & 9 & 5 & 5 & 3 & - & - & 38 & 13 \\
\hline Total(\%) & & $33(10.8)$ & $16(5.2)$ & $5(1.6)$ & $3(1.0)$ & $2(0.7)$ & - & $204(66.5)$ & $103(33.5)$ \\
\hline
\end{tabular}

$(\mathrm{FL}=$ farmland, $\mathrm{BL}=$ bushland, $\mathrm{FO}=$ forest, $\mathrm{GL}=$ grassland, $\mathrm{L} . \mathrm{f}=\mathrm{L}$. flavopunctatus, $\mathrm{A} . \mathrm{d}=\mathrm{A}$. dembeensis, $\mathrm{A} . \mathrm{a}=\mathrm{A}$. abyssinicus, $\mathrm{S} . \mathrm{a}=\mathrm{S} . \mathrm{albipes}, \mathrm{M} . \mathrm{m}=\mathrm{M}$. Mahomet, D. $\mathrm{m}=$ D. mystacalis, $\mathrm{C}$. $\mathrm{f}=\mathrm{C}$. fumosa, $(-)=$ shows absence of trapped individuals $)$.

During the entire study period, a mean of $8341 \mathrm{~g} /$ hectare biomass of live trapped rodents was recorded from all habitat types (Table 4). A mean biomass of 1269 and $1114 \mathrm{~g} /$ hectare of rodents was collected during the wet and dry seasons, respectively. The highest biomass record was obtained from the farmland habitat $(4151 \mathrm{~g} /$ hectare), which accounted to $49.8 \%$ of the total biomass record. Whereas, the lowest biomass recorded was obtained from the forest habitat (513 $\mathrm{g} /$ hectare). The second habitat with highest biomass record was grassland (1843 $\mathrm{g} /$ hectare), followed by bushland habitat with $1834 \mathrm{~g} /$ hectare. Out of the overall livetrapped species of rodents, the maximum biomass was recorded for $L$. flavopunctatus(3384 g/hectare) and the lowest was for $C$. fumosa $(20 \mathrm{~g} /$ hectare $)$.

Table 4. Biomass (g/hectare) of live-trapped rodents from the different habitats during the wet and dry seasons. Numbers in bracket show individuals captured.

\begin{tabular}{|c|c|c|c|c|c|c|c|}
\hline \multirow{2}{*}{ Species } & \multirow{2}{*}{$\begin{array}{l}\text { Mean body weight } \\
\text { (g) }\end{array}$} & \multicolumn{3}{|c|}{ Habitat type } & \multirow[b]{2}{*}{ FO } & \multirow[b]{2}{*}{ GL } & \multirow{2}{*}{ Mean biomass } \\
\hline & & Season & FL & BL & & & \\
\hline \multirow[t]{2}{*}{ L.f } & 65.7 & Wet & $920(14)$ & $1774(27)$ & - & $1248(19)$ & 3384 \\
\hline & & Dry & $329(5)$ & $986(15)$ & - & $1511(23)$ & \\
\hline \multirow[t]{2}{*}{ A.d } & 85.4 & Wet & 3074 (36) & - & - & - & 1708 \\
\hline & & Dry & $171(2)$ & $171(2)$ & - & - & \\
\hline \multirow[t]{2}{*}{ A. $a$} & 58.1 & Wet & $174(3)$ & - & - & - & 1801 \\
\hline & & Dry & $3428(59)$ & - & - & - & \\
\hline \multirow[t]{2}{*}{ S. $a$} & 52.8 & Wet & - & $528(10)$ & $687(13)$ & $264(5)$ & 1136 \\
\hline & & Dry & - & $158(3)$ & $318(6)$ & $317(6)$ & \\
\hline \multirow[t]{2}{*}{ M.m } & 10 & Wet & $80(8)$ & $30(3)$ & $10(1)$ & $110(11)$ & 245 \\
\hline & & Dry & $90(9)$ & $20(2)$ & $10(1)$ & $140(14)$ & \\
\hline \multirow[t]{2}{*}{ D. $m$} & 12 & Wet & - & - & - & - & 48 \\
\hline & & Dry & - & - & - & $96(8)$ & \\
\hline \multirow[t]{3}{*}{ C.f } & 20 & Wet & $40(2)$ & - & - & - & 20 \\
\hline & & Dry & - & - & - & - & \\
\hline & Mean total (\%) & & $4151(49.8)$ & $1834(22.0)$ & $513(6.1)$ & $1843(22.1)$ & 8341 \\
\hline
\end{tabular}

( $\mathrm{FL}=$ farmland, $\mathrm{BL}=$ bushland, $\mathrm{FO}=$ forest, $\mathrm{GL}=$ grassland, $L . f=L$. flavopunctatus, $A . d=$ A. dembeensis, $A . a=$ A. abyssinicus, $S . a=S$. albipes, $M . m=M$. Mahomet, D. $m=$ D. mystacalis, $C$. $f=C$. fumosa,$(-)=$ shows absence of trapped individuals).

The overall number of pregnant female rodents and embryo count for each species during the wet and dry seasons are given in Table 5. A total of 15 pregnant females were trapped during all trapping period. Except for $D$. mystacalis, pregnant females were captured for the remaining five snap-trapped species. The maximum and minimum number of pregnant females was recorded for $A$. dembeensisand M. mahomet, respectively. There was seasonal difference in the total number of snap-trapped pregnant females $\left(\mathrm{x}^{2}=0.6, \mathrm{df}=1, \mathrm{P}<0.05\right)$. The number of embryos of pregnant females also showed seasonal variation among species as well as within the same species. For most species, the left horn embryo implantation was higher than the right one.

The mean percentages of stomach content of snap trapped rodents during the wet and dry seasons given in Table 5. The percentage frequency of plant matters in the stomach was higher than animal matters in all species. The stomach contents of L. flavopunctatus and S. albipes contained relatively higher frequency of animal matter. Percentages of seed and stem in most stomach contents were higher during the dry season. The percentage of leaves in all stomach contents was higher during the wet season. Higher percentage of animal matter was recorded during the wet 
season. The percentage of unknown materials was higher in the stomach samples collected during the dry season.

Table 5. The number of pregnant females, embryo count and mean percentage of stomach content composition for the snap-trapped species during the wet and dry seasons.

\begin{tabular}{|c|c|c|c|c|c|c|c|c|c|c|}
\hline \multirow{2}{*}{ Species } & \multirow{2}{*}{ Season } & \multirow{2}{*}{$\begin{array}{l}\text { No. of pregnant females } \\
\text { trapped }\end{array}$} & \multirow{2}{*}{$\begin{array}{l}\text { No. of embryos } \\
\text { recorded }\end{array}$} & \multicolumn{4}{|c|}{ Plant matters (\%) } & \multicolumn{3}{|c|}{ Animal matters (\%) } \\
\hline & & & & $\mathbf{S}$ & St & $\mathbf{L}$ & $\mathbf{R}$ & $\mathbf{W}$ & $\mathbf{A}$ & $\mathbf{U N}$ \\
\hline \multirow[t]{2}{*}{ L. flavopunctatus } & Wet & 2 & $3-4$ & 5.9 & 13.1 & 48.6 & 9.5 & 6.2 & 8.5 & 8.2 \\
\hline & Dry & 2 & 3 & 16.7 & 25.4 & 29.3 & 11.9 & 0 & 4.1 & 12.6 \\
\hline \multirow[t]{2}{*}{ A. dembeensis } & Wet & 5 & $3-7$ & 17.1 & 23.8 & 45.1 & 8.2 & 0 & 0.9 & 4.9 \\
\hline & Dry & 1 & 4 & 12.3 & 27.3 & 29.9 & 15.2 & 0 & 0 & 15.3 \\
\hline \multirow[t]{2}{*}{ A. abyssinicus } & Wet & - & - & 16.4 & 10.6 & 65.4 & 1.8 & 0 & 0 & 5.8 \\
\hline & Dry & 3 & $4-7$ & 22.5 & 19.3 & 38.8 & 6.1 & 0 & 1.9 & 11.4 \\
\hline \multirow[t]{2}{*}{ S. albipes } & Wet & 1 & 7 & 5.6 & 14.7 & 22.9 & 15.6 & 9.7 & 16.3 & 15.2 \\
\hline & Dry & 1 & 4 & 9.6 & 25.9 & 23.9 & 20.4 & 0 & 9.5 & 10.7 \\
\hline \multirow[t]{2}{*}{ M. Mahomet } & Wet & 1 & 7 & 21.4 & 23.8 & 26.3 & 12.4 & 1.4 & 2.5 & 12.2 \\
\hline & Dry & - & - & 32.4 & 26.2 & 19.1 & 8.8 & 0 & 2.2 & 11.3 \\
\hline
\end{tabular}

$(\mathrm{S}=$ seed, $\mathrm{St}=$ stem, $\mathrm{L}=$ leaf, $\mathrm{W}=$ worm, $\mathrm{A}=$ arthropods, $\mathrm{UN}=$ unknown materials and bait, (-) indicates absence)

\section{Discussion}

The overall species abundance in the current study area did not show seasonal variation. However, the abundance of each species within the different habitats showed seasonal variations. For instance, the total number of $A$. dembeensis in the farmland was high during the wet season. But, it was outnumbered by its close relative $A$. abyssinicus during the dry season. Other species, such as C. fumosa and $D$. mystacalis were captured during one of the two seasons. During the dry season, grassland and farmland habitats showed increase in the total number of individuals captured; whereas the bushland as well as the forest habitats had less capture. Such seasonal fluctuation was frequently related to the abundance of vegetation cover, availability of food and water.

According to Sidorowicz (1960), different weather conditions can influence the mass appearance of rodents. For example, rainfall can influence different aspects of a given ecosystem. For many species of rodents, breeding often appears to take place during the rainy season (Teylor and Green, 1976). Food shortage and reduced ground cover might be the main reasons for the declined number of rodents in the bushland and forest habitats (Delany, 1964). During the wet season, farmers move their livestock into the mountain vegetation areas to protect their farmland. Cattle were observed grazing in the grassland habitat. Such effect was absent after harvest. The absence of such adverse effects and the presence of good ground cover during the dry season, might have favoured rodents to reproduce, leading to higher trap success.

In this study, trap success between habitats showed seasonal variation. The highest trap success was obtained from the farmland habitat during both seasons. Forest habitat was with the least trap success during both seasons. A mean trap success of $12.7 \%$ was recorded from the present study area. This was relatively lower than the previous findings from different parts of Ethiopia. For instance, Bekele (1996a) has obtained $9.1 \%$ from Menagesha-Suba State Forest; Datiko et al. (2007) have obtained 17.6\% from Arbaminch Forest and Farmlands; Habtamu and Bekele (2008) have also obtained 38.6\% from Alatish National Park. Climatic factors, vegetation type, availability of food, and human interference might have contributed to the less trap success of rodents from the present study area.

There was significant variation in the success of trapping of the male and female individuals in the current investigation. The highest trap success for the males could be associated with their high rate of mobility. Trapping success for females was less during both seasons. This might be related with their reproductive behaviour. For instance, Odhiambo and Oguge (2003) have explained that males make wider field excursions than females, which usually care for the litters. This might have limited the mobility of females and, hence lowering their trap success. Higher trap success for juveniles during the wet season could be due to the higher rate of breeding in the wet season.

The highest biomass (1269 $\mathrm{g} /$ hectare) of rodents from the present study area was obtained during the wet season. The total biomass recorded varied among habitats. The highest biomass record was obtained from the farmland habitat; whereas the forest habitat was with the lowest biomass record (Table 4). The high biomass record from the farmland habitat could be related to the highest trap success of Arvicanthis spp. during both seasons. In consistent with, Gebresilassie et al. (2005), the presence of sufficient food supply in the farmlands could have contributed for better biomass record of rodents from the present study area.

The highest embryo count among the rodents was recorded during the wet season. During the dry season, less number of pregnant females was obtained for L. flavopunctatus, $S$. albipes and A. abyssinicus. According to Boutin (1990), the presence of good quality and quantity of food in a given habitat may have significant effect on the time of reproduction, litter size and body growth rate of rodents. There was also seasonal variation in the proportion of plant and animal matter obtained from the stomach contents of each species (Table 5). This shows omnivores and opportunistic feeding behaviour of the trapped individuals. Similarly, Kasso et al. (2010) have obtained comparable result from the stomach content analysis 


\section{Conclusion}

Based on the statistical data obtained, there was no seasonal variation on the total live-trapped rodents. In contrast, the relative abundance of small mammals showed far more marked significant variation across habitats. This could be mainly attributed to population fluctuation in some species and capturing of some species only in one of the two seasons.

\section{References}

[1] Bekele, A. (1996a). Population dynamics of the Ethiopian endemic rodents Praomys albibesin the Menagesha State Forest. J. Zool., Lond. 238: 1-12.

[2] Bekele, A.andCorti, M. (1997). Forest blocks and altitude as indicators of Myomysalbipes (Rüppell 1842) (Mammalia: Rodentia ) distribution in Ethiopia. Trop. Zool. 10: 287-293.

[3] Bekele, A. and Leirs, H. (1997). Population ecology of rodents of maize field and grassland in central Ethiopia. Belg. J. Zool. 127: $39-48$.

[4] Andreo,V., Lima, M., Provensal, C., Priotto, J. and Polop, J. (2008). Population dynamics of two rodent species in agroecosystems of central Argentina: intra-specific competition, land-use, and climate effects. Pop. Ecol. 51: 297- 306.

[5] Auffray, J., Renaud, S. and Claudae, J. (2009). Rodent biodiversity, human health and pest control in a changing environments. Kasetsart J. (Nat. Sci.). 43: 83-90.

[6] Avenant, L. N. and Cavallini, P. (2007). Correlating rodent community structure with ecological integrity, Tussen-dieRiviere Nature Reserve, Free State Province, South. Integ. Zool. 2: 212-219.

[7] Boutin, S. (1990). Food supplementation experiments with terrestrial vertebrates: patterns, problems and the future. Can. J. Zool. 68: 203-220.

[8] Delany, M. J. and Monro, R.H. (1985). Movement and spatial distribution of the Nile rat in Kenya. J. Trop. Ecol. 1: 111-130.
[9] Delany, M. J. (1964). A study of the ecology and breeding of small mammals in Uganda. Proc. Zool. Soc. Lond. 142: 347370.

[10] Datiko, D., Bekele, A. and Beley, G. (2007). Feeding ecology of pest rodents from Arbaminch forest and farmlands, Ethiopia. SINET: Ethiop. J. Sci. 30: 127-134.

[11] Feldhamer, G. A., Drickamer, L. C., Vessey, S. H., Merritt, J. F. and Krajewski, C. (2007). Mammalogy: Adaptation, Diversity and Ecology, 3rd edn. The Johns Hopkins University Press, Baltimore, pp. 643.

[12] Kindgon, J. (1997). The Kingdon Field Guide to African Mammals. A \& C Black Pulishers Ltd., London, pp. 476.

[13] Kasso, M.,Bekele, A. and Hemson, G. (2010). Species composition, abundance and habitat association of rodents and insectivores from Chilalo-Galama Mountain range, Arsi, Ethiopia. Afr. J. Ecol. 48: 1105-1114.

[14] Odhiambo, C. O. and Oguge, N. O. (2003). Patterns in rodent pest distribution in a Maize cropping system in the Kenyan Rift Valley. In: Rats, Mice and People: RodentBiology and Mangement, pp. 217-219, (Singleton, G. R, Hinds, L. A., Krebs, C. J., and Spratt, D. M., eds). Australian Center of International Agricultural Research, Canberra.

[15] Mengistu, S. andBekele, A. (2003). Geographic variation in the Ethiopian common Mole-rat (Tachyoryctessplendens) based on morphometry. Ethiop. J.Biol. Sci. 2: 73-89.

[16] Sidorowicz, J. (1960). Effect of the weather on the capture of Micromammalia, Rodentia. Bialowieza9: 139-157.

[17] Habtamu, T. andBekele, A.(2008). Habitat association of insectivores and rodents of Alatish National Park, northwestern Ethiopia. Trop. Ecol. 49: 1-10.

[18] Taylor, K. D. and Green, G. (1976). The influences of rainfall on diet and reproduction in four African rodent species. $J$. Zool., Lond. 180: 367-389.

[19] Vaughan, T. A., Ryan, J. M. and Czaplewski, N. J. (2000). Mammalogy, 4th edn. Thomson Learning, Inc., Philadelphia, pp. 565.

[20] Gebresilassie, W., Bekele, A., Belay, G. and Balakrishnan, M. (2005). Population structure of rodents in Maynugus irrigation field, northern Ethiopia. Int.J. Ecol. Environ. Sci. 31: 337-342. 